\title{
Л.И. Грацианская
}

\section{ТВОРЧЕСКАЯ ЛАБОРАТОРИЯ СТРАБОНА}

\begin{abstract}
Аннотация В статье подводятся итоги многолетней работы автора над текстологическим исследованием характера компилятивной деятельности Страбона в «Географии» и обосновывается вывод о творческом характере компилятивной деятельности географа.

Ключевые слова: Страбон, «География», механическая компиляция, творческая компиляция, источник, воззрения, характер, авторское начало, система, план.
\end{abstract}

Summary The article summarizes the results of the author's many years of work on a textual study of the nature of the compilation activity of Strabo in «Geography» and substantiates the conclusion about the creative nature of the compilation activity of the geographer.

Keywords: Strabo, «Geography», mechanical compilation, creative compilation, source, views, character, author's principle, system, plan.

Творческая лаборатория Страбона - феномен, мало кем из ученого мира признаваемый. Соответственно он почти не исследован и, как мне представляется, доныне исследуется мало. Надо сказать, что до последней трети XIX в. господствовала идущая от Средневековья достаточно высокая оценка сочинения Страбона с точки зрения творческой оригинальности, но с этого времени она сменилась резко отрицательной оценкой творческой самостоятельности его труда. Причем эта оценка, утвердившись сначала в немецкой, а вслед за этим во французской и англоязычной историографии, была воспринята и историографией отечественной. Попытка Х. Бутцера привлечь внимание к оригинальным научным заслугам географа ${ }^{1}$ успеха не имела.

1 Butzer H. Über Strabo's Geographica, insbesonders über Plan und Ausfürung des Werkes zu seinen Vorgängern. Frankfurt-a-M., 1887. S. 5-8. Cp.: Sollima F. Le fonti di Strabone nella geografia della Sicilia. Messina, 1897. P. 45. 
$\mathrm{O}$ «механистичности» Страбоновой компиляции говорили с тех пор многие ${ }^{2}$. Наиболее отчетливо эту точку зрения выразил М.И. Ростовцев в «Скифии и Боспоре»: «В контаминации своих источников он (Страбон. - Л.Г.) не проявил ни особого таланта, ни особого желания скрыть швы» ${ }^{3}$. Вторая точка зрения на характер географии состоит в том, что Страбон сюжетно и идейно целиком зависит от своих источников, но стилистически обрабатывает компилируемое ${ }^{4}$.

Особняком стоит фундаментальный труд В. Али, вышедший посмертно, где комментируются отдельные пассажи «Географии» и их источники В этом исследовании чувствуются попытки представить творческую составляющую работы географа, но поскольку «География» не рассматривается Али специально как литературное единство, то и четко выраженной мысли о творческой оригинальности и целостности произведения Страбона там нет.

Появившиеся в конце 80 -гг. XX в. содержательные работы перуджийской группы исследователей «Географии» также этого вопроса практически не касаются, хотя не только останавливаются на толковании отдельных фрагментов «Географии», но и прослеживают ряд текстологических и идейных закономерностей по всему тексту ${ }^{6}$.

В 2000 г. вышла монография (на базе доктората) Д. Дуэк, где сделана попытка включить творчество Страбона и его фигуру как ученого и литератора в широкий эллинско-римский культурный контекст. Но лишь в последней, шестой, главе этой работы речь частично идет о творческих особенностях самой «Географии»7. В вышедшем через 11 лет переиздании этой монографии шестая глава осталась без изменений ${ }^{8}$.

2 Историография вопроса приведена в: Honigmann E. Strabon 3 // Pauly's Real encyclopädie der Classischen Altertumswissenschaft. Stuttgart. 1931. Hbd. 7. Sp. 102-103; более позднюю см.: Грацианская Л.И. «География» Страбона. Проблемы источниковедения // Древнейшие государства на территории СССР. 1986. М., 1988. С. 155-175; Strabone. Saggio di bibliografia 1469-1978 a cura di A.M. Biraschi, P. Maribelli, G.D. Massaro, M.A. Pagnotta. Perugia, 1981.

3 Ростовцев М.И. Скифия и Боспор: Критическое обозрение памятников литературных и археологических. Л., 1925. С. 41.

4 Wolski J. Les études sur texte de Strabon. Charisteria Sinko quinquaginta abhinc annos amplissimis in philosophia honoribus ornato ab amicis collegis discipulis. Varsaviae; Wratisclaviae, 1951. S. 292-293.

5 Aly W. Strabon von Amaseia. Untersuchungen über Text, Aufbau und Quellen der Geographica. Bonn, 1957.

${ }^{6}$ Strabone. Contributi allo studio della personalità e dell'opera. Perugia. Universitetà delgi studi, 1986. Vol. II.

7 Dueck D. Strabo of Amasia. A Greek Man of Letters in Augustan Rome. Abingdon, Oxom, 2000.

8 Dueck D. Strabo of Amasia. A Greek Man of Letters in Augustan Rome. L.; N. Y., 2011. P. $145-187$. 
В 2005 г. группой страбоноведов из разных стран выпущен сборник «Strabo's Cultural Geography. The Making of Kolossourgia», где освещаются различные аспекты труда географа от его гомеровских и поэтических штудий до философских рефлексий и от конкретных представлений о той или иной стране до его общеэтнологических воззрений ${ }^{2}$. Но и там о творческом начале в «Географии» ничего не сказано.

Представляется необходимым отметить также деятельность еще двух исследователей-страбоноведов, работающих на рубеже XX и XXI вв. Это, в первую очередь, И. Энгельс, написавший содержательный труд «Augusteische Oekumenegeographie und Universalhistorie im werk Strabon's von Amaseia», где затрагиваются вопросы биографии Страбона и влияния его философских и политических взглядов на подачу материала в «Географии», а также высказывается ряд предположений о составе «Исторических записок», рассматривается широкое полотно предшественников Страбона и дается ряд исследований по конкретике страбоновых описаний людей и местностей. Творческая составляющая работы географа в этой монографии также опущена ${ }^{10}$.

Отмечу деятельность К. Кларк, выпустившей в 1997 г. содержательную статью с полемическим названием «In Search of the Author of Strabo's "Geography"», а спустя два года монографию «Between Geography and History. Hellenistic Contributions of the Roman World» ${ }^{11}$. Исследовательница вплотную подошла к определению творческого начала в «Географии», но полноценного развития этой идее не дала.

В начале 70-х гг. XX в. Сектор истории древнейших государств на территории СССР Института истории СССР АН СССР под руководством В.Т. Пашуто начал работу над «Сводом древнейших иностранных источников по истории народов СССР». Мне достался Страбон. Выбрав все тексты, которые относились к территории тогдашнего СССР, и попытавшись их комментировать, я довольно быстро поняла, что вряд ли смогу это сделать, не впадая в локальный утилитаризм, если не уясню себе, что же представляет собой данное сочинение в целом, во имя чего оно написано, каковы философские, политические, географические, исторические и естественно-научные воззрения его автора, какими источниками и, глав-

9 Strabo's Cultural Geography. The Making of a Kolossurgia / Ed. by D. Dueck, H. Lindsay, S. Pothecary. Cambridge, 2005.

${ }^{10}$ Engels $J$. Augusteische Oikumenegeographie und Universalhistorie im Werk Strabons von Amaseia. Stuttgart, 1999 (Geographica Historica. Bd 12).

${ }^{11}$ Clarke K.J. In Search of the Author of Strabo's Geography // Journal of Roman Studies. 1997. № 87. P. 92-110; Clarke K. J. Between Geography and History. Hellenistic Contributions of the Roman World. Oxford, 1999. 
ное, как он пользовался, сколь риторичен был его подход к изложению материала и многое другое. Найти ответы на все эти вопросы в предшествующей и современной для того времени литературе я не могла, поскольку посвящена она была в основном источникам Страбона. В ней разными авторами уверенно приписывались разные куски из Страбона разным античным источникам. Часто одно и то же место «Географии» отдавалось нескольким источникам, в то время как для самого Страбона места в его сочинении практически не оставалось. Очень популярна была среди исследователей теория «основного источника» (Hauptquelle), когда большие отрывки из сочинений Страбона приписывались одному автору ${ }^{12}$.

Исследование текста Страбона по всем этим параметрам заняло более 10 лет. В результате в ежегоднике «Древнейшие государства на территории СССР» была издана монография ““География” Страбона. Проблемы источниковедения» ${ }^{13}$. Монография и лежащая в основе ее кандидатская диссертация стали первыми опытами исследования всего текста Страбона с вышеуказанных позиций, как в отечественной, так и в зарубежной историографии. К сожалению, работа была написана и опубликована только на русском языке, что помешало зарубежным исследователям воспользоваться ее результатами.

В процессе исследования памятника с вышеуказанных позиций для меня стала очевидна большая творческая работа Страбона над «Географией», в значительной степени определяющая возможности использования этого сочинения как исторического источника. Страбон подчеркивает преемственность и однородность жанров своего исторического и географического сочинений, определяя их как ن் работает как историк, но в «Географии» четко дает понять, что география для него - не просто фон исторических событий, как это было у Полибия, но равноправный компонент историко-географического знания и исследования ${ }^{15}$.

Дошедший до нас труд Страбона предназначен для наставления и развития будущего государственного деятеля проримского толка ${ }^{16}$. Впрочем, он, с точки зрения его автора, интересен и небесполезен и более широкому

${ }^{12}$ Примеры и ссылки см.: Гращианская Л.И. «География» Страбона... С. 34-46.

${ }^{13}$ Там же. С. 6-175.

${ }^{14}$ Strab., I, 1, 23; XI, 9, 3; XVII, 1, 36 etc.

${ }^{15}$ Грацианская Л.И. Роль и назначение географии в системе геополитических и политических представлений Страбона // Восточная Европа в древности и Средневековье: Миграция, расселение, война как факторы политогенеза: XXIV чтения памяти члена-корреспондента АН СССР Владимира Терентьевича Пашуто. М., 2012. С. 70-73.

${ }^{16}$ Strab., I, 1, 16; 21-23 et al. 
кругу читателей ${ }^{17}$. Таким образом, сочинение Страбона носит дидактический характер, что влечет за собой определенные закономерности в выборе фактического материала для изложения и специфические формы его подачи. Страбон декларирует необходимость излагать только то, что может быть полезным и нужным предполагаемому адресату. Он останавливается на способах научения, например, на необходимости занимательности и разного рода литературных приемов, служащих этой цели ${ }^{18}$ и, в частности, на роли мифологического или полумифологического для лучшего восприятия при научении, поскольку мифы сладки, всем известны и способствуют скорейшему восприятию изложенного ${ }^{19}$.

«География» написана компилятивным методом, что является вполне закономерным для времени и обстоятельств ее создания. Вопрос лишь в характере этой компиляции. Компилятивный метод присущ античной литературе, как греческой, так еще в большей степени и римской, на разных этапах ее развития с очень древних времен. Компиляция, равно как и сюжетный плагиат, ни греками, ни римлянами никогда не оценивалась отрицательно. Наоборот, литературные каноны предписывали ему брать сюжеты из общеизвестного запаса: мифологии и генеалогии. Подобно тому, как на надгробных плитах писались имена отца, а то и деда умершего, так и литературное произведение должно было иметь своих предшественников в мифах или литературе. Причем ограничение это касалось не только содержания (сюжета, действия, в какой-то степени, идей), но и формы, которые взаимно обуславливались. Эта предопределенность темы происходила не только из стремления автора (пересказчика, компилятора) сделать более достоверным свое детище - иель, но и обуславливалась известной фатальностью античного мышления - предпосылка, нашедшей яркое отражение еще в творчестве Гомера, а также заинтересованностью автора (и читателя) не в конечном пункте развития сюжета, не в том, «что будет дальше», а в процессе. Античной литературе архаического и классического (а отчасти и эллинистического) времени не свойственен интерес к концу произведения, который вовсе не является кульминацией: важно действо. Писатель-беллетрист (поэт, драматург) сообщает сведения с точки зрения их познавательности давно и в достаточной мере известные: знают Ахилл и Медея, что должно с ними случиться, знает об этом и античный читатель. Интерес же его сосредоточен на промежуточных событиях, на искусстве

${ }^{17}$ Strab., I, 1, 13; 17; 20-22; II, 5, 1; 17 et al.

${ }^{18}$ Грацианская Л.И. «География» Страбона... С. 96-98 и др.

${ }^{19}$ Strab., I, 2, 8-9; 19; VII, 7, 10; X, 3, 23; XV, 3, 18; XVII, 3, 3 et al; Грацианская Л.И. «География» Страбона... С. 78-79, 135, 146-152. 
описания: априорное знание исхода позволяет целиком сосредоточиться на психологической глубине и языковых и образных красотах всего произведения.

Сообщение литературным произведением чего-то нового с познавательной точки зрения стало его функцией значительно позже по двум линиям: литературы сочиненной, авантюрной - беллетристики, что впоследствии развивается и окончательно определяется как роман (в какой-то мере поздняя драма-комедия), и литературы научной, т. е. историко-географической и естественнонаучной. Роднит же эти линии еще долго элемент грядущей новизны содержания.

С этими линиями связано сюжетное и авторское начало в античной литературе, которое доселе проявлялось лишь в форме (языке, стиле, отчасти и композиции), да в относительной свободе выбора сюжета. Но если в романе или поздней драме развитие авторского начала ведет к сокращению компилятивного элемента и сюжетного плагиата, то в литературе научной, где целью изложения является истина бывшего (научная достоверность рассказываемого), роль этих элементов неуклонно растет. Здесь дело в различии цели создания двух родов литературы: первая предназначена для услаждения, вторая - для познания, познания любым способом, в частности, услаждением.

Страбон считает, что целью научного (историко-географического) сочинения должна быть истина, однако в отличие, скажем, от Полибия, Диодора Сицилийского или Лукиана, допускает в него элементы мифического, говорит о возможности излагать нечто историческое в мифологической форме для легкости усвоения и восприятия. Научение любым способом и услаждением также - такова исходная позиция автора «Географии» и его цель ${ }^{20}$.

Труд Страбона, относясь по материалу своему и манере изложения к литературе научной, целями написания (воспитание) сближается с литературой художественной: потому-то и трудно отнести его просто к жанру землеописания или географо-исторического трактата, коль скоро в произведении этом имеются элементы и комментария, и грамматического произведения, и фольклора, и новеллы, - словом всего, что могло положительно воздействовать на начинающего государственного деятеля рубежа нашей эры (но - увы! - не воздействовало) и что счастливо дает современному источниковеду материал не только глобально-исторический, но и разный другой, в том числе бытовой. Эта неканоничность, неоднородность жанра и выделяет «Географию» как исключительное явление литературы. Исто-

${ }^{20}$ Strab., I, 2, 8-9; Грацианская Л.И. «География» Страбона... С. 148-153. 
рик получает из нее самые разнообразные сведения от известий о «войнах, засухах, морах, потопах» до пикантных анекдотов о женщинах и содержателе притона ${ }^{21}$.

Дискуссионным является и порядок написания Страбоном его грандиозного труда. Молчаливое допущение большей частью исследователей строго последовательного составления «Географии», по-видимому, является принятием того, что должно быть доказано, за отправную точку доказательной системы $^{22}$. Мне этот порядок представляется несколько иным: из большого количества набросков, заметок, конспектов прочитанного, фиксаций услышанного и увиденного, записей собственных соображений Страбон собирает свой труд. Собирает по заранее продуманному и, может быть, даже письменно намеченному и зафиксированному плану: общетеоретические части, описание Европы в определенной последовательности областей, аналогичным способом скомпонованное описание Азии, потом - Африки. Однако это вовсе не предполагает, что европейские части появились в окончательном виде до азиатских и африканских. Скорее всего, продумав и зафиксировав план всего сочинения ${ }^{23}$, географ далее работал над отдельными его частями не обязательно в той последовательности, в какой они представлены в окончательном варианте (аналогичным образом, по-видимому, работал Эфор ${ }^{24}$ ). К этой идее когда-то близко подошел Ф.Г. Мищенко, рассматривая состояние книг VIII-IX вв. в рукописной традиции ${ }^{25}$. Относительно книг I-II (так называемые prolegomena) это предположение переходит в уверенность ${ }^{26}$. Структурное построение отдельных частей «Географии», описывающих выделенные Страбоном как единое целое районы, удачно проследил в свое время М.И. Ростовцев: 1. перипл, 2. исторические справки, 3. общее описание страны с историческими справками ${ }^{27}$. Добавлю, что место морского перипла может занимать речной перипл, периегеса или описание по карте 28 . Кроме того, периплу-периегесе крупных или легко выделяемых по формально-картографическому принципу районов

\footnotetext{
${ }^{21}$ Грацианская Л.И. «География» Страбона... С. 94.

${ }^{22}$ Там же. С. 39-43.

${ }^{23}$ Strab., III, 1, 1; cp.: XVII, 1, 36.

${ }^{24}$ Подробнее см.: Грацианская Л.И. «География» Страбона... С. 68-74.

${ }^{25}$ Мищенко Ф.Г. Древняя рукопись «Географии» Страбона, открытая в 1875 г. в аббатстве Гроттаферрата базилианским монахом Джузеппе Коццою // Университетские известия (Киев). 1876. № 5. С. 358-371.

${ }^{26}$ Подробнее см.: Грацианская Л.И. «География» Страбона... С. 39-44.

${ }_{27}^{27}$ Ростовцев М.И. Страбон как источник для истории Боспора // Сборник статей в честь проф. В.П. Бузескула: Издан по поводу тридцатилетия его преподавательской деятельности. Харьков, 1914. С. 368.

${ }^{28}$ Подробнее см.: Грацианская Л.И. «География» Страбона... С. 96-98.
} 
(Иберия, Италия, Сицилия, вся ойкумена и др.) всегда предшествует общая математико-образная характеристика формы, а также основных особенностей ландшафта, иногда климата или восприятия региона (ойкумена хламида, Иберия - шкура быка и др. $)^{29}$.

Творческий характер компиляции Страбона и личностные моменты прослеживаются на материале лексики (терминология, предложные употребления, синонимика), синтаксиса и стилистики этого произведения. Проявляется он и в системе ссылок на использованные источники, равно как и в понятийном аппарате автора ${ }^{30}$.

Система ссылок на источники разработана Страбоном достаточно четко. Например, на 55 тойбнеровских страниц III книги встречается 99 ссылок на конкретные и неконкретные источники, а также 24 ссылки на свой текст, причем иногда вторичное упоминание встречается достаточно далеко от первичного. В 40 случаях индивидуальный подход автора к информации проявляется в модальности («пожалуй», «видимо», «кажется», «должно быть», и т. д.). Таким образом, каждые 10 строк текста являют в той или иной степени следы активной работы компилятора над источником. Нельзя также сбрасывать со счета тот факт, что после такой переработки сведения приобретали ощутимую печать страбоновских воззрений ${ }^{31}$.

Самый предмет изложения и полемические принципы построения «Географии» предполагают сообщение по каждому поводу более одного однотипного факта. При механической компиляции естественны были бы и лексические повторения, однако они практически отсутствуют за теми редкими исключениями, когда исполняют стилистическую функцию, т. е. сделаны заведомо. Число случаев предумышленного подбора синонимики для выражения аналогичных явлений говорит о пристальном внимании географа к стилистической стороне текста.

Из анализа текста «Географии» с достаточной очевидностью следует, что все, что дается Страбоном «от себя», ему и принадлежит по праву ли аутентичности, образования, разработки источников, опроса свидетелей и т. д., т. е. прошло через память и относится к реальному багажу знаний,

${ }^{29}$ Подробнее см.: Там же. С. 97.

${ }^{30}$ Грациинская Л.И. Место политической истории Боспора в «Географии» Страбона. // Древнейшие государства на территории СССР. Ежегодник. 1975. М., 1976. С. 6-20; Грацианская Л.И. Социально-политическая терминология в «Географии» Страбона (ки́рıь) // Восточная Европа в древности и Средневековье. М., 1978. С. 84-92; Грацианская Л.И. Особенности компилятивного метода Страбона (определение истинного-ложного) // Методика изучения древнейших источников по истории народов СССР. М., 1978. С. 76-91; Грацианская Л.И. Оí лєрі у Страбона // Проблема античной истории и культуры. Ереван, 1979. Т. 1. С. 433-440; Грачианская Л.И. «География» Страбона... С. 93-126.

${ }^{31}$ Грачианская Л.И. «География» Страбона... С. 107-109. 
а не переписано некритически непосредственно с источника. Ему же принадлежит активная роль отбора и компоновки материала, а также его стилистической и терминологической обработки согласно представлениям рубежа нашей эры. Географ же - создатель достаточно жесткой и логически обоснованной композиции своего сочинения.

Следует добавить также, что Страбон часто строит свое изложение, основываясь на принципах школьных риторик ${ }^{32}$. Создавая «Географию», он использует как книжные источники, так и внекнижные. Исследование разветвленной иерархии этого использования необходимо не только для определения методов работы географа с источниками, но и для оценки достоверности с исторической точки зрения приводимой информации. Эта работа проводилась мной много лет и частично опубликована в монографии, а частично в вышедших после монографии статьях.

Анализ терминологии (терминов и «терминологизирующих» слов) географа плодотворен, но по причине размытости границ между первыми и вторыми, а также принимая во внимание некоторую условность терминологии в литературном произведении, часто не позволяет использовать его результаты однозначно. И все же тотальная выборка исследуемого термина из текста (обязательно с сопутствующим контекстом) позволяет определить его понимание и использование географом ${ }^{33}$.

При исследовании творческого метода Страбона, как мне кажется, следует особое внимание уделить так называемым повторам, которые не есть результат недоработанности текста, но намеренный композиционный прием. Из анализа их можно сделать вывод об активном владении географом значительной частью материала, как книжного, так и внекнижного, а также о характере использования этого материала, часто указывающем на цель и причину написания конкретного места «Географии» ${ }^{34}$.

Я умышленно не говорю здесь о литературных стереотипах, используемых Страбоном, поскольку это отдельная большая тема. Отмечу только, что выявление такого рода стереотипов необходимо при источниковедческом использо-

\footnotetext{
32 Подробнее см.: Там же. С. 106-109; Грацианская Л.И. Страбон и риторика // Восточная Европа в древности и Средневековье. Проблемы источниковедения. Чтения памяти В.Т. Пашуто. М., 1990. С. 39-40.

${ }^{33}$ Грацианская Л.И. «География» Страбона... С. 113-126; Грацианская Л.И. Некоторые замечания об ойкосе терминологическом и ойкосе текстологическом // Боспор Киммерийский и варварский мир в период античности и Средневековья. Ойкос. VII боспорские чтения. Керчь, 2006. С. 85-88; Грацианская Л.И. О соотнесенности различных смысловых компонентов термина «полис» в диахронии // XIII Боспорские чтения. Боспор Киммерийский и варварский мир в период античности и Средневековья. Проблемы урбанизации. Керчь, 2012. С. 116-118.

${ }^{34}$ Грацианская Л.И. «География» Страбона... С. 39-43, 133-136 и др.
} 
вании текста «Географии». Опускаю я и обширный, собранный мною материал о роли ассоциаций параллелей и доказательств у Страбона, что также очень важно для источниковедческого анализа «Географии», поскольку определяет в значительной степени историческую достоверность, переданного в них.

\section{Литература}

Грацианская Л.И. Место политической истории Боспора в «Географии» Страбона // Древнейшие государства на территории СССР. Ежегодник. 1975. М., 1976. C. 6-20.

Грацианская Л.И. Социально-политическая терминология в «Географии» Страбона (кúpıо૬) // Восточная Европа в древности и Средневековье. М., 1978. С. 84-92.

Грациианская Л.И. Особенности компилятивного метода Страбона (определение истинного-ложного) // Методика изучения древнейших источников по истории народов СССР. М., 1978. С. 76-91.

Грачиианская Л.И. Oí лєрі́ у Страбона // Проблема античной истории и культуры. Ереван, 1979. Т. 1. С. 433-440.

Грацииаская Л.И. «География» Страбона. Проблемы источниковедения // Древнейшие государства на территории СССР 1986. М., 1988. С. 6-175.

Грачианская Л.И. Страбон и риторика // Восточная Европа в древности и Средневековье. Проблемы источниковедения. Чтения памяти В. Т. Пашуто. М., 1990. C. 39-40.

Грацианская Л.И. Некоторые замечания об ойкосе терминологическом и ойкосе текстологическом // Боспор Киммерийский и варварский мир в период античности и Средневековья. Ойкос. VII боспорские чтения. Керчь, 2006. С. 85-88.

Грациианская Л.И. Роль и назначение географии в системе геополитических и политических представлений Страбона // Восточная Европа в древности и Средневековье: Миграция, расселение, война как факторы политогенеза: XXIV чтения памяти члена-корреспондента АН СССР Владимира Терентьевича Пашуто. М., 2012. C. 70-73.

Грацианская Л.И. О соотнесенности различных смысловых компонентов термина «полис» в диахронии // XIII Боспорские чтения. Боспор Киммерийский и варварский мир в период античности и Средневековья. Проблемы урбанизации. Керчь, 2012. С. 116-118.

Мищеенко Ф.Г. Древняя рукопись «Географии» Страбона, открытая в 1875 г. в аббатстве Гроттаферрата базилианским монахом Джузеппе Коццою // Университетские известия (Киев). 1876. № 5. С. 358-371.

Ростовцев М.И. Скифия и Боспор: Критическое обозрение памятников литературных и археологических. Л., 1925.

Ростовиев М.И. Страбон как источник для истории Боспора // Сборник статей в честь проф. В.П. Бузескула: Издан по поводу тридцатилетия его преподавательской деятельности. Харьков, 1914. С. 366-380. 
Aly W. Strabon von Amaseia. Untersuchungen über Text, Aufbau und Quellen der Geographica. Bonn, 1957.

Butzer H. Über Strabo's Geographica, insbesonders über Plan und Ausfürung des Werkes zu seinen Vorgängern. Frankfurt-a-M., 1887.

Clarke K.J. In Search of the Author of Strabo's Geography // Journal of Roman Studies (London). 1997. № 87. P. 92-110.

Clarke K.J. Between Geography and History. Hellenistic Contributions of the Roman World. Oxford, 1999.

Dueck D. Strabo of Amasia. A Greek Man of Letters in Augustan Rome, Abingdon, 2000.

Dueck D. Strabo of Amasia. A Greek Man of Letters in Augustan Rome. L.; N. Y., 2011.

Engels $J$. Augusteische Oikumenegeographie und Universalhistorie im Werk Strabons von Amaseia. Stuttgart, 1999 (Geographica Historica. Bd 12).

Honigmann E. Strabon 3 // Pauly's Real encyclopädie der Classischen Altertumswissenschaft. Stuttgart. 1931. Hbd. 7. Sp. 76-155.

Strabo's Cultural Geography. The Making of a Kolossurgia / Ed. by D. Dueck, H. Lindsay, S. Pothecary. Cambridge, 2005.

Sollima F. Le fonti di Strabone nella geografia della Sicilia. Messina, 1897.

Strabone. Saggio di bibliografia 1469-1978 a cura di A.M. Biraschi, P. Maribelli, G.D. Massaro, M.A. Pagnotta. Perugia, 1981.

Strabone. Contributi allo studio della personalità e dell'opera. Perugia. Universitetà delgi studi, 1986. Vol. II.

Wolski J. Les études sur texte de Strabon. Charisteria Sinko quinquaginta abhinc annos amplissimis in philosophia honoribus ornato ab amicis collegis discipulis. Varsaviae; Wratisclaviae, 1951. P. 382-394. 